\title{
Role of Biochar and Fungi on PAH Sorption to Soil Rich in Organic Matter
}

\section{Anasonye, Festus}

2018-02-01

Anasonye , F , Tammeorg , P , Parshintsev , E , Riekkola , M-L \& Tuomela , M T 2018 , '

Role of Biochar and Fungi on PAH Sorption to Soil Rich in Organic Matter ' , Water, Air and

Soil Pollution , vol. 229 , no. 2 , 49 . https://doi.org/10.1007/s11270-018-3708-2

http://hdl.handle.net/10138/307851

https://doi.org/10.1007/s11270-018-3708-2

acceptedVersion

Downloaded from Helda, University of Helsinki institutional repository.

This is an electronic reprint of the original article.

This reprint may differ from the original in pagination and typographic detail.

Please cite the original version. 
Festus Anasonye ${ }^{\mathrm{a}, *}$, Priit Tammeorg ${ }^{\mathrm{b}}, \mathrm{Jevgeni}$ Parshintsev ${ }^{\mathrm{c}}$, Marja-Liis a Riekkola $^{\mathrm{c}}$, Marja Tuomela $^{\mathrm{a}}$

${ }^{a}$ Department of Food and Environmental Sciences, P.O. Box 56, Biocenter 1, FI-00014 Univers ity of Helsinki, Finland

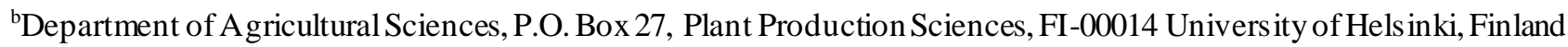

${ }^{\mathrm{c}}$ Laboratory of Analytical Chemis try, DepartmentofChemis try, A.I. Virtasen aukio 1 (P.O. Box 55) FI-00014 University of Helsinki, Finland

*Corresponding author’s e-mail address: anasonyefestus @yahoo.com

9

Key words: ACTIVATED BIOCHAR, AMENDMENT, HAPLIC ARENOSOL, ORGANIC MATTER, PYRENE, SORPTION

\section{ABSTRACT}

The use of biochar $(\mathrm{BC})$ has been suggested for remediation of contamin ated soils. This study aims to investigate the role of microorg anis ms in sorption of PAH to BC-amended soils. Fungi, es pecially the wood and litter-degrading fungi, have shown the ability for humification and to degrade recalcitrant molecules, and are thus suitable model organisms. Haplic Arenosol with high organic matter content was chosen to highlight the importance of soil org anic matter(SOM) in PAH sorption, possibly to form non-extractable residue. Basidiomycetous fungi Agrocybe praecox and Phanerochaete velutina grown on pine bark were inoculated in organic matter $(\mathrm{OM})$ rich Haplic Arenosol and $\mathrm{OM}$ poor sandy loam with either $\mathrm{BC}$ or chemically activated $\mathrm{BC}(\mathrm{ABC})$ and ${ }^{14} \mathrm{C}$ - labelled pyrene for 60 days. Fungi did not mineralize pyrene, but increased sorption up to 47-56\% in BC-amended Haplic Arenosol in comparison with controls (13-25\%) without a fungus irrespective of the presence of an adsorbent. In OM poor sandy loamonly 9-12\% of pyrene was sorbed to amended soil in the presence of fungus and adsorbent. Combining BCand fungi is an effective method for sorbing pyrene especially in high SOM soils.

\section{Introduction}

Poly aromatic hydrocarbons (PAHs) are org anic contaminants wides pread in the environment in many parts of the world. In Europe alone, PAHs contamination accounts for $11 \%$ of 340,000 contaminated sites (Liedekerke et al. 2014). A major source of PAHs contamination in soil is creos ote, a coal-tar distillate used as a preservative for power lines and crossties (Murphy and Brown 2005). PAHs are also formed by incomplete combustion of biomass. PAHs persist in the environment due their low water solubility, complex chemical structure and reduced degradation (Winquist et al. 2014; Lamichhane et al. 2016). Nearly all PAHs are highly toxic; thus, they are of concern to all life forms in soil (Chen and Liao 2006). Bioavailability of PAHs in soilis governed by soilorganic matter (SOM) content and presence of naturally occurring or added adsorbents (Macleod and Semple 2002; Cornelissen et al. 2006; Lamichhane et al. 2016). The fate of PAHs in soil 
depends on many physical, chemical and biological processes such as absorption, volatilization, photolysis, chemical degradation, and microbial degradation (Deng and Zeng 2017).

Biochar (BC) is produced frombiomass by pyrolysis and is distinguished fromother carbonaceous materials by its end use (EBC 2012). Differently fromcharcoal (often used for energy production), $\mathrm{BC}$ is used in a way that does not involve rapid mineralis ation of the photosynthetically fixed carbon back to atmosphere (EBC 2012). BC has shown capacity to sorb organic contaminants (Beesley et al. 2011; Zhu et al. 2017), however, its sorption capacity is lower compared with activated carbon (AC; Hale et al. 2011). Apart from contaminant sorption, application of BC to soil offers other advantages, such as carbon sequestration (Woolf et al. 2010; Smith, 2016), soil fertility improvement (Major et al. 2010; Jones et al. 2012; Tammeorg et al. 2014a; b; Ding et al. 2016) and reduction of $\mathrm{N}_{2} \mathrm{O}$ emissions from soil (Case et al. 2012; Angst et al. 2013; Zhu et al. 2017). Thus, BC is a relevant alternative to AC despite its moderate sorption capacity.

The influence of BC addition on soil microorganis ms have been increasingly studied (e.g. Pietikäinen et al. 2000; Lehmann et al, 2011; Abujabhah et al. 2016; Dai et al. 2016; 2017). Pores in BC can serve as home for microorganisms (Warnock et al. 2007; Quilliam et al. 2013a) and also harbour microorganisms that are not native to soils, while surfaces can provide a platform for biofilm formation (Lehmann et al, 2011, Noyce et al. 2016). Changes in microbial composition and abundance in soil following BC addition have been reported (Pietikäinen et al. 2000; Nielsen et al. 2014; Mitchell et al. 2016; Abujabhah et al. 2016; Dai et al. 2017). O’Neill et al. (2009), Grossman et al. (2010) and Taketani et al. (2013) reported higher microbial population and an increased microbial diversity in high native black carbon Anthrosols than in adjacent soils. Increase in relative abundance of soil bacteria and a decrease in soil fungi with $\mathrm{BC}$ addition has been reported and the changes was due to an increase in soil carbon content as BC may have supplied labile C substrates that favored fast growing bacteria over fungi (Khadem and Raiesi 2017). BC addition stimulates biological processes such as increases in enzyme activities and res piration rates in amended soil (AlMarzooqi and Yousef 2017). Jin (2010) observed a shift in a fungal community following $\mathrm{BC}$ amendment. The observed changes in microbial communities following $\mathrm{BC}$ amendment may also be explained by increase in nutrient availability and utilization which leads to an overall increase in soil fertility (Kolton et al. 2011; Anderson et al. 2011; Nielsen et al. 2014; Pan et al. 2016). Other key factors controlling the shifts in relative abundance and diversity of microbial populations in soil following biochar addition may include; soil physicochemical properties such as org anic matter content, $\mathrm{pH}$ and texture, type of biochar applied, incubation time and climatic conditions (Lehmann et al. 2011Farrel et al. 2013; Prayogo et al. 2013; Ogbonnaya et al. 2014; Watzinger et al. 2014; Zhu et al. 2017)

Although BC contributes greatly in sorption of PAH compounds in the BC-amended soil (Zhang et al. 2010; Chen and Yuan 2011), very little is known aboutthe role of microorg anis ms es pecially the fungi in this sorption process (Quilliam et al. 2013b; Zhu et al. 2017). PAHs in BC-amended soil can be degraded by both bacteria and fungi in soil(Rhodes et al. 2008; Quilliam et al. 2013b) as BC can enhance action of fungi in soil (García-Delgado et al. 2015). PAHs and other aromatic compounds in the amended soil can be oxidized and incorporated into SOM as non-extractable or bound residues by enzymes produced by fungi in the soil (Dec et al. 2001; Kästner et al. 2014). The processes of enhanced sorption by $\mathrm{BC}$ and enhanced formation of non-extractable or bound residues from PAH compounds by fungi in soil have been adopted as effective soil remediation strategies as they reduce the bioavailability of PAH in soil (Bollag 1992; Kästner et al. 2014; Zhu et al. 2017). The possibility that both strategies, processes of enhanced sorption by BC and enhanced formation of non-extractable or bound residues fromPAH compounds by fungi occurring in soil amended with $\mathrm{BC}$ has 
not been previously studied. PAH degradation in soil by fungi as well as sorption to BC-amended soil differs between soil types (Anyika et al. 2015). The fate of PAH in BC-amended soil may depend on the properties of the soil and BC as well as microbial composition of the amended soil (Anyika et al. 2015).

In this study, we inves tigated the role of microorganisms in sorption of PAH to BC-amended soils when combined with fungi. Pyrene, a common pollutant in PAH-contaminated soil that is not readily degraded by other microorganisms in soil was selected as a modelPAH compound. The aim was to understand the role of fungi, BC and their combined effect on the environmental fate of PAH in contaminated soil using ${ }^{14} \mathrm{C}$-pyrene-labelled compound. A particular emphasis was on the role of soil organic matter, as almost all the previous studies have been performed with OM poor soil. We hypothesized that a) the porous carbonaceous soil amendments will sorb the more PAH the higher their specific surface area and b) that PAH are more easily sorbed to biochar in low SOM soils and c) that introducing fungi to the system will further increase the sorption of PAH to high SOM soil by oxidative enzymes binding organic compounds to SOM.

\section{Materials and methods}

\subsection{Chemicals}

PAH mix, containing 16 United States Environmental Protection Agency (US-EPA) PAH compounds (acenaphthene, acenaphthylene, anthracene (ANT), benzo(a)anthracene, benzo(a)pyene (BaP), benzo(b)fluoranthene, benzo(g,h,i)perylene, benzo(k)fluoranthene, chrysene, dibenz(a,h)anthracene (DBA), fluoranthene, fluorene, indeno(1,2,3-cd)pyrene, naphthalene, phenanthrene, pyrene (PYR), and carbazole at each concentration of $2 \mathrm{mg} \mathrm{mL}^{-1}$ in dichloromethane : benzene (1:1) was purchased from AccuStandard, New Haven, CT, USA. Sodiumacetate (American Chemical Society certified grade), sodiumchloride (analytical grade), isopropanol (analytical g rade) and toluene (HPLC grade) were purchased from Sigma-Aldrich (St. Louis, MO, USA). 1,1'-binaphthyl (97\% purity) used as the intemal standard during PAH analysis was purchased from Acros Organics, (Geel, Belgium). 4,5,9,10- ${ }^{14} \mathrm{C}-$ pyrene (specific activity $2.035 \mathrm{GBq} \mathrm{mmol}^{-1}$, radiochemical purity $\geq 99 \%$ ) was purchased from Sigma-Aldrich (St. Louis, MO, USA).

\subsection{Soils and adsorbents used in the experiment}

Three non-contaminated soils were used in the experiments with BC and one PAH contaminated soil was used for PAH extraction method optimization and screening of fungi. The first soil has a texture class of sandy loamand was sampled from a depth of 0-20 cm (a non-agricultural soil) from Biocenter 1 surroundings of Viikki campus of University of Helsinki, Hels inki Finland $\left(60^{\circ} 22^{\prime} \mathrm{N}, 25^{\circ} 01^{\prime} \mathrm{E}\right)$. The second soil has a texture class of s and and was sampled fromtop 0 $20 \mathrm{~cm}$ depth (an agricultural soil) from Viikki agricultural field, University of Helsinki, Hels inki Finland $\left(60^{\circ} 22^{\prime} \mathrm{N}\right.$, $25^{\circ} 02^{\prime} \mathrm{E}$ ). The third soil is classified as an Entic Haplocryod (Soil Survey Staff, 1998) or a Haplic Arenosol (FAO UNESCO, 1997) and is simply referred here as Haplic Arenosol, was collected in the vicinity of Forest Field Station of the University of Helsinki in Juupajoki, $\left(61^{0} 84^{\prime} \mathrm{N}, 24^{0} 26^{\prime} \mathrm{E}\right)$ (corresponds to Hyytiälä soil in Ilvesniemi et al. 2000). Soil samples were stored at $4^{0} \mathrm{C}$ before use. PAH contaminated soil which is described in detail in Winquistet al. (2014), was used to screen for fungal growth on BC-amended contaminated soil and for PAH extraction optimization.

BC was prepared from spruce wood chips as described in Tammeorg et al. (2014a). AC used was a commercial product from coconut shell charcoal(AC004; Activated Carbon Technology UK Limited, Billingham, UK). Particle size of AC 
was $2.36-4.75 \mathrm{~mm}$. ABC was produced fromBC (see the next section). Prior to the experiment with soil, $\mathrm{BC}$ an $\mathrm{d} A \mathrm{BC}$ were sieved with $<2 \mathrm{~mm}$ mesh. AC was used as received from the producer.

pH of adsorbents, soiland soil amended with adsorbents was measured from 1:2.5 $\left(\mathrm{v} \mathrm{v}^{-1}\right)$ sus pension in deionized water, while moisture contents were meas ured gravimetrically by drying a known mas s of soil overnight at $105^{\circ} \mathrm{C}$. Soil organic matter content (SOM) was measured by placing dried soil at $550^{\circ} \mathrm{C}$ for 4 hours and calculated as loss on ignition. The specific surface area of BC, ABC and AC was measured by the Brunauer, Emmett, and Teller (BET) nitrogen adsorption method measured with Micromeritics surface analyzer (Micromeritics Tristar II 3020, Norcros s, GA, USA) at Tampere University of Technology, Finland. The elemental carbon, hydrogen and nitrogen content of samples was measured by using a VarioMaxelementalanaly zer (Elemental Analy sensysteme GmbH, Hanau, Germany). Cation exchange capacity (CEC) of adsorbents and soil was analyzed by adopting a method described by Mitchell et al. (2013) with some modifications. A s ample of $0.5 \mathrm{~g}$ of adsorbent or $1 \mathrm{~g}$ of soil with or without adsorbent was u sed. The solution was analyzed using flame photometer (Model410, Corning, New York, USA). The contribution of native black carbon to total organic carbon content of the soil was estimated using the peroxide/weak nitric acid digestions method described by Kurth et al. (2006), except that soil was ground to $0.63 \mu \mathrm{m}$ particle size. The total carbon remaining, estimated as oxidation-resistant elemental carbon was considered to be the soil native black carbon (Rumpel et al. 2006).

\subsection{Activated biochar production}

Activated biochar (ABC) was produced fromBC as described by Lalhruaitluanga et al. (2011). In brief, sieved BC was added to potassium hydroxide $(\mathrm{KOH})$ solution of various concentrations $(1,10,20,40,60$ and $80 \%)$. The mixture was stirred for $24 \mathrm{~h}$ at a speed of $150 \mathrm{rpm}$. ABC was separated from $\mathrm{KOH}$ solution by centrifugation at $10,000 \mathrm{rpm}$ for $10 \mathrm{~min}$ and thoroughly washed with deionized water, to remove excess $\mathrm{KOH}$ and other impurities that might be blocking the newly created pores on the surface of the activated biochar. The separated $\mathrm{ABC}$ was oven-dried at $110{ }^{\circ} \mathrm{C}$ for $24 \mathrm{~h}$ and then cooled at room temperature and stored in an air-tight container.

\subsection{PAH sorption to soil and soil amended with adsorbents}

To prepare the soil with desirable amendments, i.e. AC and ABC (1\%), and BC (1 and 2\%) (w/w) samples, soil was thoroughly mixed with an ads orbent. For each treatment, $10 \mathrm{~g}$ of soil and either AC, BC or ABC was added toa $100 \mathrm{~mL}$ glas s bottle. Soil-ad sorbent mixture in glas s bottle was spiked with $125 \mu \mathrm{L}$ of $2 \mathrm{~g} \mathrm{~L}^{-1}$ mixture of four PAHs, comprising ANT (3-rings), PYR (4-rings), BaP (5-rings) and DBA (5-rings) in dichloromethane benzene (1:1). Acetone(10 mL) was added to the mixture and mixed thoroughly to ensure homogeneous mixing of PAHs in soil. After mixing, acetone was allowed to evaporate in the hood for 3 days. The final concentration for each PAH in the soil was $25 \mathrm{mg} \mathrm{kg}^{-1}$ (i.e. total PAH concentration in the soil was $100 \mathrm{mg} \mathrm{kg}^{-1}$ ). Soils without adsorbents were spiked with the same concentration of PAHs in order to obtain control samples. The first bottles were taken for extraction immediately after acetone had evaporated, i.e. on day 3. The remaining bottles were incubated at $21^{\circ} \mathrm{C}$ in the dark for 60 days.

\subsection{PAH extraction}

PAH concentration of adsorbents was measured after Soxhlet extraction as described in Tammeorg et al. (2014a). Three PAH extraction methods were evaluated: ultrasound-assisted extraction(UAE), accelerated solvent extraction (ASE) and Soxhlet extraction (SE) for contaminated soil and details are in Fig. S1. For further analyses, ASEmethod was selected 
as it was automatic, efficient, fast, easy and environmentally safe, and PAHs were extracted as efficiently as with Soxhlet which is considered a conventional extraction method. ASEcondition used are as that described by Hilber et al. (2012).

\subsection{PAH analysis by gas chromatography-mass spectrometry (GC-MS)}

PAHs were analysed with gas chromatography (Agilent Technologies 6890N, USA) equipped with mas s spectrometry (MS Agilent 5973N) by injecting $1 \mu$ Lof the extract using splitless injection mode. Separation was doneon Zebron High performance ZB -5ms GC column (30 m, $0.25 \mathrm{~mm}$ internal diameter, $0.25 \mu \mathrm{m}$ film thicknes s) fromPhenomenex, USA. A deactivated retention gap (Agilent Technologies) of $2 \mathrm{~m}$ length with $0.53 \mathrm{~mm}$ internal diameter was placed before the separation column. Helium was used as a carrier gas at constant pressure of $100 \mathrm{kPa}$. The injection temperature was set to $320^{\circ} \mathrm{C}$ while the oven temperature program was as follows: $90^{\circ} \mathrm{C}(2 \mathrm{~min})$; increase of $10^{\circ} \mathrm{C} \mathrm{min}-1 \mathrm{until} 320^{\circ} \mathrm{C}$; $320^{\circ} \mathrm{C}$ (15 min). Detection was performed with MS in the electron impact mode with $70 \mathrm{eV}$ ionization energy. The ion source temperature was $150^{\circ} \mathrm{C}$ and the interface between the $\mathrm{GC}$ and the quadruple $\mathrm{MS}$ was set to $320^{\circ} \mathrm{C}$. Compounds were identified with the National Institute of Standard and Technology (NIST) library and quantification was done using internal standard method. Toluene mixtures containing varying amounts of analy tes (concentrations = 0.1, 0.5, 1.0, 2.0, $\left.4.0 \mu \mathrm{g} \mathrm{mL}^{-1}\right)$ and a cons tant amount of internal standard (1,1'-binaphthyl $5 \mu \mathrm{g} \mathrm{mL}^{-1)}$ were us ed for calibration. The limits of detection for ANT, PYR, BaP and DBA were 0.02, 0.03, 0.04 and $0.06 \mu \mathrm{g} \mathrm{mL}-1$, respectively.

\subsection{Sorption experiment}

The sorption coefficient $\left(K_{\mathrm{d}}\right)$ of ${ }^{14} \mathrm{C}$ pyrene was obtained in a batch equilibration experiment with three replicates as described by Kumariet al. (2014) with little modifications. Three millilitres from the soil solution was taken and mixed with $10 \mathrm{~mL}$ of scintillation cocktail (OptiPhase "HiSafe" 3® Perkin Elmer Inc.; Fisher Chemicals, Loughborough Leicesters hire, England). The radioactivity was measured using a liquid scintillation counter(Wallac 1411, Scintillation Products, Wallac Oy, Turku, Finland). BC and ABC-amended soils, (s andy loam, sand and Haplic Arenosol) were used in sorption experiment with two variants; 1) non-extracted soil and 2) DOC-extracted soil. DOC was extracted froms oil as described by Impellitteri et al. (2002) except that here 3 further rounds of extractions were carried out.

\subsection{Fungal strains, inoculation and screening}

Fungal strains used in this experiment were obtained from the FungalBiotechnology Culture Collection (FBCC) of the Department of Food andEnvironmental Sciences, University of Hels inki, Helsinki, Finland, and were grown on $2 \%$ malt extract agar plates and incubated at $25^{\circ} \mathrm{C}$ before the use in experiments. Basidiomycetous fungi were chosen as model organis ms due to their unique ability to decontaminate PAH contaminated soil by mineralization and humification of PAH compounds. The fungal species with FBCCnumber (is olation number is given in parenthesis) were: Agrocybe dura 478 (Mn71-2), Agrocybe praecox 476 (Tm70.84), Phanerochaete velutina 941 (T244i), Obba rivulosa 939 (T241i) (formerly known as Physisporinus rivulosus), Rhodocollybiabutyracea 626(K209) and Stropharia coronilla 480 (s tock gram B). Fungal liquid cultures were prepared according to Anasonye et al. (2015). Fungiwere incubated on autoclaved Scots pine (Pinus sylvestris) bark, until the surface of the bark was fully covered with fungal mycelium. The screening of fungal strains was performed in PAHcontaminated soil amended with either $1 \%$ or $2 \%(w / w) ~ B C$. Petri-dis hes of $9 \mathrm{~cm}$ in diameter were filled with $50 \mathrm{~g}$ of soil and $2.5 \mathrm{~g}$ pine bark with fungal my celium was placed on top of the soil. Fungal growth was examined visually once a week during 90 days of incubation at room temperature in the dark. Moisture content of the soil was kept constant by adding water if needed. 


\subsection{Sorption of ${ }^{14} \mathrm{C}$-pyrene}

180 Two fungi were selected for further experiments, namely A. praecox and P. velutina. Non-sterile sandy loam or Haplic Arenosol (10 g) was placed in a $100 \mathrm{~mL}$ glass bottle (Schott Duran laboratory glassware, Mainz, Germany) and ${ }^{14} \mathrm{C}-$ labelled pyrene was added uniformly to soil (radioactivity $2,100 \mathrm{~Bq}$ per bottle) and thoroughly mixed to ensure homogeneous result. Sand was not used in this experiment as two soil types with marked difference in SOM was prefemed. The soil was amended with either BC or ABC, $1 \%$ for sandy loam and 2\% for Haplic Arenosol (w/w). Soil mois ture content was adjusted to $40 \%$ of maximum water holding capacity using deionized water and $5 \mathrm{~g}$ of fungal inoculum growing on bark was added on top of the soil. For controlbottles, uninoculated bark was added on top of spiked soil.

Abiotic control bottles were included to account for the impact of indigenous microorganisms on pyrene sorption and degradation. For abiotic control, s oil was autoclaved before spiking with ${ }^{14} \mathrm{C}$-py rene and adding adsorbent. All treatments with three replicates were incubated at $21^{\circ} \mathrm{C}$ in the dark for 60 days. The bottles were flushed with mois tair for 15 minutes once a week. Mineralized fraction, i.e. evolved ${ }^{14} \mathrm{CO}_{2}$ was trapped during the aeration period into $10 \mathrm{~mL}$ of $1 \mathrm{M} \mathrm{NaOH}$. Radioactivity was measured from $1 \mathrm{~mL}$ of trapping solution mixed with $10 \mathrm{~mL}$ of scintillation cocktail (OptiPhase "HiSafe"). After incubation, bark with or without fungus was separated from soil by sieving. Pyrene was extracted from the soil with ASE as described earlier. The radioactivity was measured with liquid scintillation counter from $1 \mathrm{~mL}$ of toluene extract mixed with $10 \mathrm{~mL}$ of the scintillation cocktail. After toluene extraction, soil and sieved bark were combusted separately with Junitek Oxidizer (Junitek Oy, Turku, Finland). During combustion, all the carbon in the sample forms $\mathrm{CO}_{2}$, which is trapped with a mixture of $16 \mathrm{~mL}$ Lumas orb2 II and Carboluma2 scintillation liquids (1:1 v/v; Lumac LSC, Belgium) and radioactivity is measured with liquid scintillation counter. The mas s balance of ${ }^{14} \mathrm{C}$-pyrene was determined as in Valentin et al. (2013) with modifications:(1) toluene extraction (available fraction), (2) fraction bound to soil (unavailable fraction), and (3) fraction bound to bark.

\subsection{Statistical analyses}

The effects of experimental treatment combinations on the percentage of PAH sorbed were tested with a two-way analysis of variance (ANOVA) with soil type, treatment, and their interactions as fixed effects for both incubation time s ( 3 and 60 days). The effects of experimental treatment combinations on the $\mathrm{K}_{\mathrm{d}}$ and mas s balance were tested with a two and threeway analysis of variance (ANOVA), respectively with soil type, treatment, and their interactions as fixed. Means were compared using the Tukey HSD multiple pair-wise comparis on test at $\mathrm{p}<0.05$. The normal distribution of the res iduals from the models was tested with Shapiro-Wilk test and the homogeneity of variances was tested with Levene's test. If the data failed to meet the assumptions for parametric statistics, Box-Cox transformation was us ed (Box and Cox, 1964). Statistical analyses were carried out with the software package PASW v 20.0 (SPSS Corp., Chicago, USA).

\section{Results}

\subsection{Physicochemical properties of soils and ads orbents}

Haplic Arenosol had lower pH and significantly higher DOC and SOM contents compared with sandy loam and sand (Table 1). The highest content of native black carbon was recorded in Haplic Arenosol (2\% of soil total mass) while the lowest was in sandy loam soil. Elemental compositions of BC, ABC and AC were similar, but specific surface area of 

of adsorbents were below or within the recommended maximum limit set by international $\mathrm{BC}$ initiative $\left(6-30 \mu \mathrm{g} \mathrm{g}^{-1}\right.$; IBI 2015) and below the limit by European Union (12 $\mu \mathrm{g} \mathrm{g}^{-1}$; EBC 2012) for use as a soil amendment in agriculture.

\subsection{Sorption capacity of BC}

Soil types, treatments and interactions affected the percentage of PAH sorbed for all four PAHs used in this experiment (Table 3). ABC-amended sandy loam sorbed (95-100\%) PAHs in 3 days (Table S1). However, the effect seemed to be only short-lived as the sorption efficiency of $\mathrm{ABC}$ had decreased notably after 60 days of incubation. In sandy loam significantly, more pyrene was sorbed than in other soil types. AC addition to sandy loamand sand significantly enhanced pyrene sorption ( $\mathrm{p}<0.001$, Table 3, Table S1) compared to BC and ABC during a 60-day incubation period.

\subsection{Role of dissolved organic carbon (DOC)}

$\mathrm{BC}$ and $\mathrm{ABC}$ addition significantly (Figure 1, $\mathrm{p}<0.001$, Table S2) increased ${ }^{14} \mathrm{C}$-pyrene sorption to both sandy loam and sandy soils and theincrease with $\mathrm{ABC}$ in both soils were larger compared with BC. In Haplic Arenosol, BCand ABC addition had little or no effect on pyrene sorption. When DOC was removed from the soil, pyrene sorption to control sandy loamand sand without amendments significantly (Fig 1, p < 0.001) decreased although it significantly improved in Haplic Arenosol. BC and ABC additions to DOC-extracted soil significantly (Fig 1, p < 0.001, Table S2) increased pyrene sorption to sandy loam soil.

\subsection{Fungal treatment}

All the screened fungigrew to the soil amended with BC except Obba rivulosa that grew only on bark used as a carrier material in inoculation (datanot shown). Regardless of whether BC was added at 1 or $2 \%,(w / w)$ there was no difference in growth of fungi. However, two fungi, A. praecox and P. velutina were chosen for further experiment, as they have shown in previous studies to have the capability to colonize the soil, compete favorably with indigenous microorg anisms and to degrade PAH in soil (Steffen et al. 2002; Winquist et al. 2014).

There was significant difference in the levels of pyrene that was sorbed to the soils used in the study ( $p<0.001$, Table 4). The role of fungal action to pyrene sorption in $\mathrm{BC}$ or $\mathrm{ABC}$-amended soils was evaluated in two soil types. Higher levels of ${ }^{14} \mathrm{C}$-pyrene was sorbed to Haplic Arenosol incubated with fungus (47-56\%) compared with sandy loam (up to 19\%). The lowest levels of pyrene sorption in the soil were observed in autoclaved soils with BCor ABC (9-15\%), highlighting the role of indigenous microorg anisms in PAH sorption to soil. Three-way analysis of variance (ANOVA) also showed that soil type significantly influenced pyrene sorption to the bark used in the experiment $(\mathrm{p}<0.001$, Table 4$)$. Significantly higher levels of pyrene sorbed to sandy loam (27-36\%) than to Haplic Arenosol (2-7\%). There was no significant difference between the two fungal strains used in the way they caused change in sorption of pyrene to BC-amended soil. Both fungi significantly increased the sorption of pyrene to Haplic Arenosol-BC complex (Table 4). Similarly, the two 
adsorbents used had no significant difference in the way they cause changes in sorption of pyrene to soil incubated with fungi. Haplic Arenosol amended with either of the adsorbents showed increased capacity to sorb pyrene compared to OM poor soil.. Haplic There was noevolution of ${ }^{14} \mathrm{CO}_{2}$ in either control or treated soil during the entire incubation period.

\section{Discussion}

PAH sorption was maximum mostly with $\mathrm{ABC}$ in the beginning of incubation regardless of soil type. This is particularly interesting considering that $\mathrm{AChad}$ almost double $\mathrm{BET}$ surface areacompared with $\mathrm{ABC}$ or $\mathrm{BC}$, thus our first hypothesis was only partially supported by the evidence. The phenomenon could be explained by the formation of alkaline surface sites on $\mathrm{BC}$ during activation with potassiumhydroxide or wider pore size of $\mathrm{ABC}$ compared to $\mathrm{AC}$ and $\mathrm{BC}$ (de Andrés et al. 2013). Chemically activated char is known to forms urface sites leading to enhanced sorption capacity (de Andrés et al. 2013; Lamichhane et al. 2016) and less time is needed for PAH to access sorption sites in ABC than AC or BC, if pore size in $\mathrm{ABC}$ is wider. Also, alkali modified $\mathrm{BC}$ enhances $\mathrm{BC}$ sorption capacity through the formation of $\pi-\pi$ electron donor acceptor interaction between modified BC and aromatic rings of PAH (Liu et al. 2012; Zhu et al. 2017) Hence, BET surface area is not the only factor controlling PAH sorption, but other chemical and phy sical properties as well as the aliphatic regions of adsorbents play a role in contaminantssorption (Park et al. 2013). However, when ABC was aged for 60 days in soil, it was unable to retain most of the sorbed PAH. During a prolonged incubation in soil, the surface chemistry and sorption characteris tics of ABC may have been altered (Cheng and Lehmann 2009; Gibson et al. 2016), resulting in the release of already sorbed PAH. This phenomenon is ty pical to char produced by chemical activation with potassiumhydroxide and such effect was not detected with AC and BC. In a field scale experiment, Martin et al. (2012) observed release of already sorbed diuron and atrazine from $\mathrm{BC}$ in soil during aging, but when $\mathrm{BC}$ dose was increased, sorption remained stable. Thus, the ability of an adsorbent to retain the contaminant over time in soil may depend on adsorbent dose used. In our study, two doses were used, but very little or no difference was observed between doses. Further research will be required to determine whether PAH-ABC-soil complex is more stable with increased ABC dose and aging.

We investigated the role of DOC in PAH sorption to BC or ABC-amended soil. As hypothesized, higher levels of sorption were observed with sandy loam and sand, which had lower DOC concentrations in comparison with Haplic Arenosol. The result is in line with previous findings (Zhang et al. 2010; Kumari et al. 2014) where enhancement of PAH sorption in soil with BC was clearly observed in soils with low DOC and organic carbon contents. DOC as sociates strongly with BC surfaces in soil (Hale et al. 2011; Zhang et al. 2010), and SOM may block the pores of BC and reduce sorption of organic contaminants (Pignatello et al. 2006; Lian et al. 2015). After DOC was removed from soil there was enhanced PAH sorption to the Haplic Arenosol, not only to soil amended with BC, but also to control soil. This phenomenon in Haplic Arenosol could be explained by high native black carbon content compared with sandy loam and sand.

Also the third hypothesis of ours was supported by the evidence as both A. praecox and P. velutina increased sorption of pyrene to the Haplic Arenosol so that the bound fraction was approximately half of total pyrene. There seems to be a synergis tic effect between $\mathrm{BC}$ and fungi in decreasing bioav ailability and sorption of $\mathrm{PAH}$, which was earlier confimmed 
by García-Delgado et al. (2015) with low SOM soil, and our results further emphasize the role of SOM in the process. White-rot and litter-decomposing fungi are known to produce oxidative enzymes, such as laccase and manganese peroxidase, which are known to bind organic compounds to SOM through oxidative coupling (Berry and Boyd, 1984; Bollag 1992; Held et al. 1997) as well as mineralize them (Steffen et al. 2002, Tuomela et al. 1999). However, we measured no evolution of ${ }^{14} \mathrm{CO}_{2}$ during the entire incubation period. SOM influence has been observed to reduce mineralization of pentachlorophenol (Tuomela et al. 1999) and the increase of aromatic rings and addition of BC probably enhances the phenomenon as has been proved with ${ }^{14} \mathrm{C}$-labelled synthetic lignin and phenanthrene (Tuomela et al. 2002, Rhodes et al. 2008). If a contaminant is bound irreversibly to soil or BC, this can be considered as relevant remediation action (Bollag 1992). In our earlier studies (Anasonye et al. 2014 and 2015) of soil system where a white-rot fungus was grown (including P. velutina), manganese peroxidase was the main oxidative enzyme found with little or no laccase activity, but García-Delgado et al. (2015) detected both laccase and manganese peroxidase fromPAH contaminated soil with Pleurotus ostreatus. BC addition did not affect the enzy me production of the fungus. In addition to BC and SOM, bark acted as an adsorbent especially when organic matter content of soil was low, als o previously reported (Olivella et al. 2013, Winquist et al. 2014,). In addition to binding sites of the bark, bark extractives are capable of sorbing PAH (Olivella et al. 2013).

The results obtained from sterile soil with $\mathrm{BC}$ or $\mathrm{ABC}$ were compared with those obtained from non-sterile soil with similar amendments in order to show the difference in roles of biotic vers us abiotic processes in enhancement of pyrene sorption in amended soil. The presence of native microbes in soil had higher impact on pyrene sorption to the amendedHaplic Arenosol compared with the amended-sandy loam soil. Soil with high organic carbon tends to favor fungal colonization over bacteria (Zhang et al. 2015), thus Haplic Arenosol, which is rich in lignocellulosic materials, was probably more colonized with fungi capable of enhancing pyrene sorption as detected with A. praecox and $P$. velutina.

Stability of bound compound is very important as slow and continuous leaching to groundwater will pose a constant risk to the en vironment (Bollag 1992). In our system, the soil was subjected to strong extraction procedure with organic solvent to obtain the freely available fraction. The ${ }^{14} \mathrm{C}$-pyrene fraction remaining in soil after strong chemicaltreatment is most probably bound to adsorbents-SOM complex through covalent bonds, which are the most resistant to extraction and degradation (Khan et al. 1978), and should remain in soil for a very long time.

\section{Conclusions}

We found that PAH can effectively be sorbed to carbonaceous soil amendments and thus be a promising tool for remediating polluted sites. The effectiveness of biochar to sorb PAH can further be increased when activating the biochar thus improving not only its BET surface area, but also its pore morphology and surface chemistry. The method was shown to be even furtherenhanced if biochar addition is combined with treatment with basidiomycetous fungi, especially in high SOM soils. Sorption of pyrene to BC-SOM complex enhanced by fungi could help reduce the leaching of pyrene from soil to groundwater, but the results are yet to be validified under field conditions 


\section{Acknowledgements}

The authors thank Jussi Heinonsalo, Kati Hakala and Kari Steffen for providing the experimental soils, Kaj-Roger Humm for providing the guidance in working with labeled compounds. This research was funded by Maj and Tor Nessling Foundation.

\section{References}

Abujabhah, I. S., Bound, S. A., Doyle, R., Bowman, J. P. (2016). Effects of biochar and compost amendments on soil physico-chemical properties and the total community within a temperate agricultural soil. Applied SoilEcology, 98, 243253.

Al Marzooqi, F., Yousef, L.F. (2017). Biological response of a s andy soil treated with biochar derived froma halophyte (Salicornia bigelovii). Applied Soil Ecology, 114, 9-15.

Anasonye, F., Winquist, E., Räsänen, M., Kontro, J., Björklöf, K., Vasilyeva, G., Jørgensen, K. S., Steffen, K. T., Tuomela, M. (2015). Bioremediation of TNT contaminated soil with fungi under laboratory and pilot scale conditions. International Biodeterioration \& Biodegradation, 105, 7-12.

Anderson, C. R., Condron, L. M., Clough, T. J., Fiers, M., Stewart, A., Hill, R. A., Sherlock, R. R. (2011). Biochar induced soil microbial community change: implications for biogeochemical cy cling of carbon, nitrogen and ph osphorus. Pedobiologia, 54, 309-320.

Angst, T. E., Patterson, C. J., Reay, D. S., Anderson, P., Peshkur, T. A., Sohi, S. P. (2013). Biochar diminishes nitrous oxide and nitrate leaching from diverse nutrient sources. Journal of Environmental Quality, 42, 672-682.

Anyika, C., Majid, Z. A., Ibrahim, Z., Zakaria, M. P., Yahya, A. (2014). The impact of biochars on sorption and biodegradation of polycyclic aromatic hydrocarbons in soils - a review. Environmental Science and Pollution Research, 22, 3314-3341.

Beesley,L., Moreno-Jiménez, E., Gomez-Eyles, J. L., Harris, E., Robinson, B., Sizmur, T. (2011). A review of biochars' potential role in the remediation, revegetation and restoration of contaminated soils. Environmental pollution, 159, 32693282.

Berry D. F., Boyd, S. A. (1984). Oxidative coupling of phenols and anilines by peroxidase: structure-activity relationships. Soil Science Society of America Journal, 48, 565-569.

Bollag, J. M. (1992). Decontaminating soil with enzymes. Environmental Science \& Technology, 26, 1876-1881.

Case, S. D., McNamara, N.P., Reay, D. S., Whitaker, J. (2012). The effect of biochar addition on $\mathrm{N}_{2} \mathrm{O}$ and $\mathrm{CO}_{2}$ emis sions from a sandy loam soil-the role of soil aeration. Soil Biology and Biochemistry, 51, 125-134. 
Chen, B., Yuan, M. (2011). Enhanced sorption of polycyclic aromatic hydrocarbons by soil amended with biochar. Journal of Soils and Sediments, 11, 62-71.

350 Chen, S., Liao, C. (2006). Health risk as sessment on human exposed to environmental polycyclic aromatic hydrocarbons pollution sources. Science of the Total Environment, 366, 112-123.

Cheng, C., Lehmann, J. (2009). Ageing of black carbon along a temperature gradient. Chemosphere, 75, 1021-1027.

Cornelissen, G., Breedveld, G. D., Kalaitzidis, S., Christanis, K., Kibsgaard, A., Oen, A. M. (2006). Strong sorption of native PAHs to pyrogenic and unburned carbonaceous geosorbents in sediments. Environmental Science \& Technology, 40, 1197-1203.

Dai, Z., Hu, J., Zhang, L., Brookes, P. C., He, Y., Xu, J. (2016). Sensitive responders among bacterial and fungal microbiome to pyrogenic organic matter (biochar) addition differed greatly between rhizosphere and bulk soils. Scientific Reports, 6, 36101.

Dai Z, Hu J, Barberan A, Li Y, Brookes PC, He Y, Xu J (2017) Bacterial community composition associated with pyrogenic organic matter (Biochar) varies with pyrolysis temperature and colonization environment. Applied and Environmental Science, 2, 2 e00085-17.

de Andrés, J. M., Orjales, L., Narros, A., de la Fuente., María del Mar., Rodríguez M. E. (2013). Carbon dioxide ads orption in chemically activated carbon fromsewage sludge. Journal of the Air \& WasteManagement Association, 63, $557-564$.

Dec, J., Haider, K., Bollag, J. (2001). Decarboxylation and demethoxylation of naturally occurring phenols during coupling reactions and polymerization. Soil Science, 166, 660-671.

Deng, S., Zeng, D. (2017). Removal of phenanthrene in contaminated soil by combination of alfalfa, white-rot fungus and earthworm. Environmental Science and Pollution Research, 24, 7565-7571.

Ding, Y., Liu, Y., Liu, S., Zhongwu,L., Tan, X., Huang, X.,Zeng, G., Zhou, L., Zheng, B. (2016). Biocharto improve soil fertility. Agronomy for Sustainable Development, 36, 1-18.

EBC, 2012. 'European biochar Certificate - Guidelines for a Sustainable Production of biochar. European biochar Foundation (EBC), Arbaz, Switzerland. http://www.european biochar.org/en/download. Version 6.2E of 04th February 2016. DOI: 10.13140/RG.2.1.4658.7043.

FAO-UNESCO. (1997). Soil map of the world. Revised legend, with corrections and updates. World Soil Resources Report 60, Reprinted with updates as Technical paper 20, International Soil Reference and Information Centre, Wageningen, $140 \mathrm{p}$.

Farrell, M., Kuhn, T. K., Macdonald, L. M., Maddern, T. M., Murphy, D. V., Hall, P. A., Singh, B. P., Baumann, k., Krull, E. S., Baldock, J. A. (2013). Microbial utilis ation of biochar-derived carbon. Science of the Total Environment, 465, 288-297. 
García-Delgado, C., Alfano-Barta, I., Eymar, E. (2015). Combination of biochar amendment and mycoremediation for polycyclic aromatic hydrocarbons immobilization and biodegradation in creosote-contaminated soil. Journal of Hazardous Materials, 285, 259-266.

Gibson, C., Berry, T. D., W ang, R., Spencer, J.A., Johnston, C. T., Jiang, Y., Bird, J. A., Filley, T. R. (2016). Weathering of pyrogenic organic matter induces fungal oxidativeenzyme responsein single culture inoculation experiments. Organic Geochemistry, 92, 32-41.

Grossman, J. M., O’Neill, B. E., Tsai, S. M., Liang, B., Neves, E., Lehmann, J., Thies, J.E. (2010). Amazonian anthrosols support similar microbial communities that differ distinctly from those extant in adjacent, unmodified soils of the same mineralogy. Microbial Ecology, 60, 192-205.

Hale, S., Hanley, K., Lehmann, J., Zimmerman, A., Cornelissen, G. (2011). Effects of chemical, biological, and physical aging as well as soil addition on the sorption of pyrene to activated carbon and biochar. Environmental Science \& Technology, 45, 10445-10453.

Held, T., Draude, G., Schmidt, F., Brokamp, A., Reis, K. (1997). Enhanced humification as an in-situ bioremediation technique for 2, 4, 6-trinitrotoluene (TNT) contaminated soils. Environmental Science \& Technology, 18, 479-487.

Hilber, I., Blum, F., Leifeld, J., Schmidt, H. P., Bucheli, T. (2012) Quantitative determination of PAHs in biochar. a prerequisite to ensure its quality and safe application. Journal of Agricultural and Food Chemistry 60, 3042-3050.

IBI (2015) Standardized product definition and product testing guidelines for biochar that is used in soil. International biochar Initiative, p.15 http://www. biocharinternational.org/sites/default/files/IBI_Biochar_Standards_V2.1.pdf. Accessed 18 December 2016.

Ilvesniemi, H., Giesle,r R., van Hees, P., Magnussson, T., Melkerud, P. A. (2000). General description of the sampling techniques and the sites investigated in the Fennoscandinavian podzolization project. Geoderma 94, 109-123.

Impellitteri, C. A., Lu, Y., Saxe, J. K., Allen, H. E., Peijnenburg, W. J. (2002). Correlation of the partitioning of dissolved organic matter fractions with the desorption of $\mathrm{Cd}, \mathrm{Cu}, \mathrm{Ni}, \mathrm{Pb}$ and $\mathrm{Zn}$ from 18 Dutch soils. Environment International, $28,401-410$.

Jin, H. (2010.) Characterization of microbial life colonizing biochar and biochar -amended soils. PhD Dis sertation, Cornell University, Ithaca, NY.

Jones, D., Rousk, J., Edwards-Jones, G., DeLuca, T., Murphy, D. (2012). Biochar-mediated changes in soil quality and plant growth in a three year field trial. Soil Biology and Biochemistry, 45, 113-124.

Kästner, M., Nowak, K. M., Miltner, A., Stefan, Trapp, S., Schäffer, A. (2014). Classification and modelling of nonextractable residue (NER) formation of xenobiotics in soil - a synthesis. Critical Reviews in Environmental Science and Technology, 44, 2107-2171.

Khadem, A., Raiesi, F. (2017). Responses of microbial performance and community to corn biochar in calcareous sandy and clayey soils. Applied Soil Ecology, 114, 16-27. 
Khan, S. (1978). The interaction of organic matter with pesticides. In M. Schnitzer(Ed.), Soil organic matter: development in soil science (pp. 137-171). Amsterdam; Elsevier.

Kolton, M., Meller,H. Y., Pasternak, Z., Graber,E. R., Elad, Y., Cytryn,E. (2011). Impact of biochar application to soil on the root-associated bacterial community structure of fully developed greenhousepepper plants. Applied Environmental Microbiology, 77, 4924-4930.

Kumari, K., Moldrup, P., Paradelo, M., de Jonge, L.W. (2014). Phenanthrene sorption on biochar -amended soils: Application rate, aging, and physicochemical properties of soil. Water, Air, \& Soil Pollution, 225, 1-13.

Kurth, V., MacKenzie, M., DeLuca, T. (2006). Estimating charcoal content in forest mineral soils. Geoderma, 137, 135139.

Lalhruaitluanga, H., Prasad, M., Radha, K. (2011). Potential of chemically activated and raw charcoals of Melocanna baccifera for removal of Ni (II) and Zn (II) from aqueous solutions. Desalination, 271, 301-308.

Lamichhane, S., Krishna, K., Sarukkalige. (2016). Polycyclic aromatic hydrocarbons (PAHs) removal by sorption: a review. Chemosphere, 148, 336-353.

Lehmann, J., Rillig, M. C., Thies, J., Masiello, C. A., Hockaday, W. C., Crowley, D. (2011). Biochareffects on soil biotaa review. Soil Biology and Biochemistry, 43, 1812-1836.

Lian, F., Sun, B., Chen, X., Zhu, L., Liu, Z., Xing, B. (2015). Effect of humic acid (HA) on sulfonamide sorption by biochars. Environmental pollution, 204, 306-312.

Liedekerke, M., Prokop, G., Rabl-Berger, S., Kibblewhite and G.Louwagie. (2014). Progress in the management of contaminated sites in Europe. JRC Reference Reports, Joint Research Centre, Report EUR 26376 EN, European Commission. http://www.eea.europa.eu/data-and-maps/indicators/progress-in-management-of-contaminated-sites3/joint-research-centre-2014-progress. Accessed 06 September 2016.

Liu, P., Liu, W., Jiang, H., Chen, J., Li, W., Yu, H. (2012). Modification of bio-char derived fromfast pyrolysis of biomass and its application in removal of tetracycline from aqueous solution. Bioresource Technology, 121, 235-240.

Macleod, C. J., Semple, K.T. (2002). The adaptation of two similar soils to pyrene catabolism. Environmental pollution, $119,357-364$.

Major, J., Rondon, M., Molina, D., Riha, S. J., Lehmann, J. (2010). Maize yield and nutrition during 4 years after biochar application to a Colombian savanna oxisol. Plant Science, 333, 117-128.

Martin, S. M., Kookana, R. S., Van Zwieten,L., Krull, E. (2012). Marked changes in herbicide sorption-desorption upon ageing of biochars in soil. Journal of Hazardous Materials, 231, 70-78.

Mitchell, P. J., Dalley, T. S., Helleur, R. J. (2013). Preliminary laboratory production and characterization of biochars from lignocellulosic municipal waste. Journal of Analytical and Applied Pyrolysis, 99, 71-78. 
Mitchell, P. J., Simpson, A. J., Soong, R., Schurman, J. C., Thomas, S. C., Simpson, M. J. (2016) Biochar amendment and phosphorus altered forest soil microbial community and native soil organic matter molecular composition. Biogeochemistry, 130, 227-245.Murphy, B.L., Brown, J. (2005). Environmental forensics aspects of PAHs from wood treatment with creosote compounds. Environmental Forensics, 6, 151-159.

Nielsen, S., Minchin, T., Kimber, S., van Zwieten, L., Gilbert, J., Munroe, P., Joseph, S., Thomas, T. (2014). Comparative analysis of the microbial communities in agricultural soil amended with enhanced biochars or traditional fertilisers. Agriculture, Ecosystems \& Environment, 191, 73-82.

Noyce, G. L., Winsborough, C., Fulthorpe, R., Basiliko, N. (2016). The microbiomes and metagenomes of forest biochars. Scientific Reports, 6, 26425.

O’Neill, B., Grossman, J., Tsai, M., Gomes, J., Lehmann, J., Peterson, J., Neves, E., Thies, J. E. (2009). Bacterial community composition in Brazilian anthrosols and adjacent soils characterized using culturing and molecular identification. Microbial Ecology, 58, 23-35.

Ogbonnaya, U., Oyelami, A., Matthews, J., Adebisi, O., Semple, K. T. (2014). Influence of wood biochar on phenanthrene catabolismin soils. Environments, 1, 60-74.

Olivella, Costa, À., Fernández, I., Cano, L., Jové, P., Oliveras, A. (2013). Role of chemical components of cork on sorption of aqueous polycy clic aromatic hydrocarbons. International Journal of Environmental Research, 1, 225-234.

Pan, F., Li, Y., Chapman, S. T., Khan, S., Yao, H. (2016). Microbial utilization of rice straw and its derived biochar in a paddy Soil. Science of the Total Environment, 559, 15-23.

Park, J., Hung, I., Gan, Z., Rojas, O. J., Lim, K. H., Park, S. (2013). Activated carbon frombiochar: Influence of its physicochemical properties on the sorption characteristics of phenanthrene. Bioresource Technology, 149, 383-389.

Pietikäinen, J., Kiikkilä, O., Fritze, H. (2000). Charcoal as a habitat for microbes and its effect on the microbial community of the underlying humus. Oikos, 89, 231-242.

Pignatello, J. J., Kwon, S., Lu, Y. (2006). Effect of natural org anic substances on the surface and adsorptive properties of environmental black carbon (char): attenuation of surface activity by humic and fulvic acids. Environmental Science \& Technology, 40, 7757-7763.

Prayogo, C., Jones, J. E., Bending, G. D. (2013). Impact of biochar on mineralisation of C and N from soil and willow litter and its relation ship with microbial community biomass and structure. Biology and Fertility of Soils, 50, 695-702.

Quilliam, R.S., Glanville, H. C., Wade, S.C., Jones, D. L. (2013a). Life in the charosphere-does biochar in agricultural soil provide a significant habitat for microorganisms? Soil Biology and Biochemistry, 69, 287-293.

Quilliam, R. S., Rangecroft, S., Emmett, B. A., Deluca, T.H., Jones, D. L. (2013b). Is biochar a source or sink for polycyclic aromatic hydrocarbon (PAH) compounds in agricultural soils? GCB Bioenergy, 5, 96-103.

Rhodes, A., Carlin, A., Semple, K. T. (2008). Impact of Black Carbon in the Extraction and Mineralization of Phenanthrene in Soil. Science of the Total Environment, 42, 740-745. 
Rumpel, C., Alexis, M., Chabbi, A., Chaplot, V., Rasse, D. P., Valentin, C., Mariotti, A. (2006). Black carbon contribution to soil organic matter composition in tropical sloping land under slash and burn agriculture. Geoderma 130, 35-46.

Smith, P. (2016). Soil carbon sequestration and biochar as negative emis sion technologies. Global Change Biology,22, $1315-1324$.

Soil Survey Staff. (1998). Keys to Soil Taxonomy. United States Department of Agriculture/Natural Resources Conservation Service.

Steffen, K., Hatakka, A., Hofrichter, M. (2002). Removal and mineralization of polycyclic aromatic hydrocarbons by litter-decomposing basidiomycetous fungi. Applied Microbiology and Biotechnology, 60, 212-217.

Tammeorg, P., Parviainen, T., Nuutinen, V., Simojoki, A., Vaara, E., Helenius, J. (2014a). Effects of biochar on earthworms in arable soil: avoidance test and field trial in boreal loamy sand. Agriculture, Ecosystems \& Environment, 191, 150-157.

Tammeorg, P., Simojoki, A., Mäkelä, P., Stoddard, F. L., Alakukku, L., Helenius, J. (2014b). Short-termeffects of biochar on soil properties and wheat yield formation with meat bone meal and inorganic fertiliser on a boreal loamy sand. Agriculture, Ecosystems \& Environment, 191, 108-116.

Tuomela, M., Lyytikäinen, M., Oivanen, P., Hatakka, A. (1999). Mineralization and conversion of pentachlorophenol (PCP) in soil inoculated with the white-rot fungi Trametes versicolor. Soil Biology and Biochemistry, 31, 65-74.

Tuomela, M., Oivanen, P., Hatakka, A. (2002). Degradation of synthetic ${ }^{14} \mathrm{C}$-lignin by various white-rot fungi in soil. Soil Soil Biology and Biochemistry, 34, 1613-1620.

Valentín, L., Oesch-Kuisma, H., Steffen, K. T., Kähkönen, M. A., Hatakka, A., Tuomela, M. (2013). Mycoremediation of wood and soil froman old sawmill area contaminated for decades. Journal of Hazardous Materials, 260, 668-675.

Watzinger, A., Feichtmair, S., Kitzler, B., Zehetner, F., kloss, S., W immer, B., Zechmeister-Boltenstern, S., Soja, G. (2014). Soil microbial communities responded to biochar application in temperate soils and slowly metabolized ${ }^{13} \mathrm{C}$ labelled biochar as revealed by ${ }^{13} \mathrm{CPLFA}$ analyses:results froma short-termincubation and pot experiment. European Journal of Soil Science, 65, 40-51.

Warnock, D. D., Lehmann, J., Kuype,r T. W., Rillig, M. C. (2007). Mycorrhizal responses to biochar in soil-concepts and mechanisms. Plant Soil, 300, 9-20.

Winquist, E., Björklöf, K., Schultz, E., Räsänen, M., Salonen, K., Anasonye, F., Cajthaml, T., Steffen, K. T., Jørgensen, K. S., Tuomela, M. (2014). Bioremediation of PAH-contaminated soil with fungi-From laboratory to field scale. International Biodeterioration \& Biodegradation, 86, 238-247.

Woolf, D., Amonette, J. E., Street-Perrott, F. A., Lehmann, J., Joseph, S. (2010). Sustainable biochar to mitigate global climate change. Nature Communications, 1, 56. 
508 Zhang, Q., Zhou, W., Liang, G. Q., Sun, J. W., Wang, X. B., He, P. (2015). Distribution of soil nutrients, extracellular 509 enzyme activities and microbial communities across particle-size fractions in a long-termfertilizer experiment. Applied $510 \quad$ Soil Ecology, 94, 59-71.

511 Zhang, H., Lin, K., Wang, H., Gan, J. (2010). Effect of Pinus radiata derived biochar on soil sorption and desorption of 512 phenanthrene. Environmental pollution, 158, 2821-2825.

513 Zhu, X., Chen, B., Zhu, L., Xing, B. (2017). Effects and mechanisms of biochar-microbe interactions in soil improvement 514 and pollution remediation: a review. Environmental pollution, 227, 98-115.

Figure caption

517 Figure 1 Sorption parameter $\left(\mathrm{K}_{\mathrm{d}}\right)\left(\mathrm{L} \mathrm{kg}^{-1}\right)$ of ${ }^{14} \mathrm{C}$-pyrene in soil with (on left) and without DOC (on right) with or without $5181 \%(\mathrm{w} / \mathrm{w}) \mathrm{BC}$ or ABC. Dis solved organic matter (DOC) was extracted from the soil with deionized water three times 